\title{
FUNCIONAMENTOS DE INSTITUIÇÕES EM CENAS DE USO DE CRACK: UM ESTUDO ETNOGRÁFICO
}

\section{THE WORK OF INSTITUTIONS IN CRACK SCENES: AN ETHNOGRAPHIC STUDY}

\author{
Erick Araujo iD (0000-0002-8993-5456)
}

${ }^{1}$ Universidade Federal de Ouro Preto, Programa de Pós-Graduação em História, Estágio PósDoutoral, Mariana, Minas Gerais, Brasil.

<ericklaraujo@gmail.com>

Resumo Na pesquisa que deu origem a este artigo, realizada na cidade do Rio de Janeiro, de 2013 a 2015, analisaram-se os funcionamentos das instituições em relação às cenas de uso de crack e as pessoas que as frequentam, com o objetivo de torná-los inteligíveis. Na perspectiva do encontro entre o Consultório na Rua e aquelas pessoas presentes nessas cenas e que se tornaram, ou não, suas usuárias, joga-se luz sobre as relações tecidas entre essa população e o crack , o próprio Consultório na Rua e instituições como a polícia, a assistência social e outros serviços de saúde. Com base nos dados produzidos pela etnografia, podem ser compreendidos dois polos de ação institucional: um que se aproxima do fazer morrer ou deixar viver, exercendo mesmo um poder soberano de decisão; e aquele segundo o qual a instituição se oferece como apoio existencial e, para tanto, modifica-se a partir do encontro com aquelas pessoas que busca atender. Conclui-se que as inovações, existentes e possíveis, nos serviços de saúde decorrem desse funcionamento no qual as instituições, por meio do que se chamou 'responsabilidade institucional', se abrem às transformações acionadas por uma 'potência minoritária'.

Palavras-chave população em situação de rua; crack; Sistema Único de Saúde.
Abstract In the research that originated this article, which was performed in the city of Rio de Janeiro, Brazil, between 2013 and 2015, we analyzed the work of the institutions regarding the crack scenes and the people who attend those institutions, with the goal of making them intelligible. In the perspective of the encounter between the Doctor's Office in the Street (Consultório na Rua, in Portuguese) and those people present in those scenes who either have become users or not, we shed light on the relationships developed between this population and crack, between the Doctor's Office in the Street and institutions such as the Police, social aid and other health services. Based on the data produced with the ethnography, one can comprehend two hubs for institutional action: one that is close to making someone die or letting them live, which indeed has a sovereign decision power, and the one according to which the institution offers itself as existential support and, therefore, changes after the encounter with those people it means to care for. We conclude that the existing and possible innovations in the health services are due to this way of working in which the institutions, through what was called 'institutional responsibility,' open themselves to transformations triggered by a 'minority power.

Keywords homeless persons; crack; Unified Health System.

(cc) BY Este é um artigo publicado em acesso aberto sob uma licença Creative Commons. 


\section{Introdução}

Acompanhou-se, de 2013 a 2015, o encontro de uma equipe de atenção básica à saúde $(\mathrm{AB})$, chamada Consultório na Rua (CnaR) Manguinhos, com pessoas que se tornaram, ou não, suas usuárias. Inicialmente restritos às ruas de Manguinhos, os encontros passaram a ocorrer também em ruas, calçadas e linhas de trem de diferentes localidades na Zona Norte da cidade do Rio de Janeiro, como Jacarezinho e Nova Holanda, na Maré. Nesses encontros, tornou-se visível que se lidava, também, com o encontro entre uma certa droga, o crack, e muitos corpos, inclusive aqueles institucionais. Portanto, além do CnaR, joga-se luz sobre as ações de outras instituições - a polícia, a assistência social, outros serviços de saúde e o tráfico. Ações que puderam ser observadas durante o trabalho de campo foram relatadas pela equipe ou então pelos usuários do serviço. Assim, com base na etnografia, pretendeuse apresentar uma análise dos funcionamentos institucionais nas chamadas cracolândias.

Dois pontos precisam ser destacados acerca dessa pretensão: ao dizer 'com base na etnografia', aponta-se para o fato de que não se trata de um relato da pesquisa de campo, mas sim de uma articulação dos dados nela produzidos com aqueles de outras pesquisas; não se diz 'funcionamentos institucionais' de modo aleatório. Objetivou-se destacar, a um só tempo, um enfoque na prática de certos coletivos humanos e o caráter específico de tais coletivos agrupados sob o termo instituição - termo polissêmico, cujo uso intenta-se justificar por meio de uma digressão teórica guiada pelo trabalho de campo.

A pesquisa que originou este artigo foi aprovada em 10 de dezembro de 2013 pelo Comitê de Ética em Pesquisa do Hospital Universitário Antônio Pedro, Faculdade de Medicina da Universidade Federal Fluminense, CAAE: 18683413.9 .0000 .5243$.

\section{Notas preliminares sobre a noção de instituição}

A noção de 'instituição' perpassa o texto. Sob ela são aglomeradas equipes de saúde, da assistência social, da polícia, a mídia, assim como o tráfico de drogas. A indistinção que caracteriza seu uso não é um acaso. Por um lado, sabe-se que "a polissemia da noção de instituição facilita confusões" (Ardoino e Lourau, 2003, p. 22); por outro, tal polissemia se apresenta como um possível guia para uma circunscrição do que se quer dizer quando se fala em instituição. Para tal circunscrição parecem necessárias duas considerações, ditas nietzschianas. 
No curso O poder psiquiátrico, Foucault (2006) faz algumas críticas ao seu livro A história da loucura na idade clássica (Foucault, 2012). Dentre elas, especificamente em relação ao capítulo "O nascimento do asilo" (Foucault, 2012), está a referente ao uso da noção de 'instituição':

(...) parece-me que ela encerra certo número de perigos porque, a partir do momento que se fala em instituições, fala-se, no fundo, ao mesmo tempo de indivíduos e de coletividade; o indivíduo, a coletividade e as regras que as regem já estão dadas, e, por conseguinte, pode-se precipitar aí todos os discursos psicológicos ou sociológicos (Foucault, 2006, p. 19).

(...) importante, portanto, não são as regularidades institucionais, mas muito mais as disposições de poder, as redes, as correntes, as intermediações, os pontos de apoio, as diferenças de potencial que caracterizam uma forma de poder e que, creio, são precisamente constitutivos ao mesmo tempo do indivíduo e da coletividade (Foucault, 2006, p. 20).

Em suma, "aquilo com que se tem que lidar, antes de lidar com as instituições, são as relações de força nessas disposições táticas que perpassam as instituições" (Foucault, 2006, p. 20). Daí a noção de 'instituição' ser apresentada por Foucault (2006) como uma fechadura enferrujada com a qual não se pode ir muito longe.

Ao se partir para a segunda consideração, explicita-se o motivo da denominação 'nietzschiana'. Em Nietzsche, a "história de uma coisa é, em geral, a sucessão de forças que dela se apoderam, e a coexistência de forças que lutam para dela se apoderar" (Deleuze, 2010, p. 4). O “objeto é, ele mesmo, força, expressão de uma força"; logo, "há mais ou menos afinidade entre o objeto e a força que dele se apodera": "não há objeto (fenômeno) que já não seja possuído, tendo em vista que, nele mesmo, ele é não uma aparência, mas o aparecimento de uma força. Toda força está, portanto, numa relação essencial com uma outra força" (Deleuze, 2010, p. 7).

Há, assim, dois estratos complementares para análise: um no qual pretendese 'ir muito longe'; outro cuja pretensão é manter-se na proximidade. No primeiro, são consideradas as forças - seus começos, suas potências afirmadoras ou negadoras da vida - que atravessam, configuram e modificam as coisas, incluindo nesse termo os corpos individuais, coletivos e institucionais. No segundo estrato, lida-se com o modo como tais forças se cristalizam momentaneamente, dão uma configuração - um certo modelo a ser formalizado ou não - e impulsionam um funcionamento específico daquilo que está em foco. Quando se fala em 'poder', então, denota-se um conglomerado de sistematizações - tecnologias - dessas forças que passarão a atravessar e configurar o socius de certo modo. Ao ter em foco as instituições, pretende-se atentar a 
coexistência e o funcionamento dessas tecnologias em um campo restrito; daí uma proposição de circunscrição da noção de instituição: complementaridade entre cristalização e gerenciamento prático da multiplicidade de correlações de força ao mesmo tempo imanente e constitutiva do corpo institucional e do campo de atuação (Foucault, 2007). Essa complementaridade produz graus de estabilidade existencial, algo como meios de estabelecer filtros, transferências, desvios e bloqueios sobre certas forças. Tal estabilidade institucional articulase menos com uma "lógica, uma série de prescrições ou leis" (Baremblitt, 1998, p. 31), fundante e aplicada aos casos concretos, do que com situações nas quais deve-se produzir ativamente essa estabilidade por meio do gerenciamento que tende à perpetuação de um modelo, por meio, inclusive, de seus desvios e variações.

A cristalização de certa correlação de forças produz um modelo segundo o qual se estabelecem ou se detectam as "variações de desvianças" (Deleuze e Guattari, 1996, p. 45). Estabelecimento "que tanto pode marcar uma tolerância sob certas condições quanto indicar um inimigo que é necessário abater a qualquer preço" (Deleuze e Guattari, 1996, p. 45). Destarte, ao se impor como 'centro existencial', uma instituição gruda forma e conteúdo; passa a expressar, e não deixar escapar, uma infinidade de existenciais. Aí se vislumbra a coexistência do poder soberano, disciplinar, e da biopolítica (Foucault, 2008), pois estes postulam certos atributos, modelos, eventos e formas de agir com referência a significantes sociais (criminoso, operário, louco, população). Pressente-se, também, algo como uma "integração generalizada" (Guattari, 1988 , p. 221). Uma sociedade de integração (Ribeiro, 2018) na qual o que está em foco são todas as conexões e fugas criativas possíveis, pois a mera existência delas já é frontal ao estado de coisas presente. Trata-se, então, de seduzir o 'gérmen'; desviá-lo, fazê-lo nutrir-se e orbitar ao redor da instituição. Fala-se, destarte, da instalação da instituição como centro existencial. Uma operação que busca configurar, a um só golpe, o 'já aí' e o 'em vias de'.

\section{A saúde do cidadão e a saúde na rua}

O CnaR de Manguinhos, bairro-favela na Zona Norte do Rio de Janeiro, surge de uma demanda da primeira Conferência Local de Saúde da região. Nela, argumentou-se que a existência de cenas abertas de uso de crack seria uma particularidade de Manguinhos. Assim, o CnaR atuaria, predominantemente, em relação àquelas pessoas em situação de rua classificadas como usuárias de crack.

Formalmente, o objetivo das equipes de CnaR é facilitar o acesso da população em situação de rua aos serviços de saúde (Antunes, 2013). No entanto, os relatos de usuárias e usuários do serviço, colhidos durante o trabalho de 
campo, mostraram algo diferente: ouviam dizer que em unidades de pronto atendimento (UPAs) e unidades básicas de saúde (UBSs) que a equipe de rua não estava presente para realizar o acolhimento; que não havia atendimento na unidade sem apresentação de documentação; e, de modo mais direto, que não se atendia pessoa de rua. Relatos de não acolhimento, que fazem ver certa pressão em direção à cristalização do CnaR como equipe especializada, cujo público seria exclusivo.

Nesse sentido, tem-se como hipótese, seguindo os enunciados da equipe, que casos de miíase, infecções, problemas em consolidações de fraturas, entre outros, poderiam não existir se essas pessoas fossem atendidas previamente e de modo adequado. Hipótese fortalecida pela expressão de um usuário do CnaR para se referir a seu atendimento de modo apressado em uma UPA.

Pergunta-se: o CnaR, de mecanismo para facilitação de acesso aos serviços de saúde, tende a se somar às emergências (Engstrom e Teixeira, 2016) como únicos serviços possíveis para essa população? Se todas as cidadãs e os cidadãos têm direito a acessar os serviços do Sistema Único de Saúde (SUS), o que pensar desse termo 'cidadão' em relação àquelas pessoas mantidas sem atendimento? Parece necessária certa cautela na busca por respostas.

Por um lado, ao se considerar o campo social dado, torna-se perceptível um funcionamento policialesco do termo cidadão como um dispositivo de detecção de desvios - quem é cidadão, quem está menos e mais afastado do modelo de cidadão - e, ao mesmo tempo, um dispositivo de estabelecimento de penas - quais as ações a serem tomadas de acordo com essa distância. Assim, parece pertinente afirmar que o não acolhimento configura-se como uma pena imposta àquela pessoa que guarda certa distância de um modelo de cidadania. Por outro lado, há um uso ingênuo dos termos cidadã(o) e cidadania, que parece indicar uma esperança de que funcionem como atos de fala - como aquele do juiz quando transforma o acusado em condenado - e façam surgir cidadã(o)s de modo instantâneo onde se tinha algo diferente, exterior ao que usualmente se apresenta como sendo o conteúdo dessas expressões. Mas um ato de fala não se faz por si só: o ato de fala do juiz tem certo efeito porque é dito a partir de certa situação, em um tribunal, com prisões esperando o condenado e guardas para o encaminharem. Há um funcionamento conjunto de certos elementos imateriais e elementos materiais. Caso o juiz diga a mesma coisa em outra situação, o ato ganha outra configuração. Em suma, diz-se que o acesso aos serviços do SUS é direito do cidadão; cabe perguntar quais são os efeitos concretos, em um campo social dado, dessa expressão.

Parece ser exemplar o caso no qual uma senhora viu que o CnaR Manguinhos tinha acabado de atender algumas pessoas em uma cena aberta de uso de crack, se aproximou da equipe e, em tom de cobrança, questionou: "O que 'nós' temos que fazer para ser atendidos como 'eles'?" Olhava e apontava em direção ao local onde as pessoas que tinham acabado de ser atendidas estavam 
e depois voltava a encarar rigidamente a equipe. Dizia que aquelas pessoas não enfrentavam as filas, a demora e o descaso como ela enfrentava quando precisava de atendimento em alguma clínica ou hospital; e parecia-lhe não terem que lidar com a falta de compromisso que ela percebia por parte da equipe de saúde da família, responsável pela área onde residia. Um pesquisador ouviu enunciado semelhante em uma UBS em Porto Alegre (RS), durante o acompanhamento do trabalho do CnaR da cidade: "Por que essa mulher aí [moradora de rua] vai ser atendida na nossa frente se ela chegou depois? Ela não trabalha, só se chapa e tem preferência?" (Abib, 2014, p. 111).

Trata-se de uma distinção entre 'nós' e 'eles'. Tal distinção varia em uma escala extensa. Há um polo de pura violência: “como disse o vigia da prefeitura que trabalha no Caps [Centro de Atenção Psicossocial]: 'eles' [os usuários de crack] são 'um bando de vagabundos' (sic), tem que 'descer o pau' (sic) neles" (Romanini e Roso, 2014, p. 372). Há outro mais sutil: erigem-se meios de adequação a um modelo de cidadão. A imposição da abstinência como 'requisito' para certos tratamentos ou para o acolhimento é um exemplo. Caso não se abstenha das drogas, não se receberá tratamento. Tal imposição não se restringe às comunidades terapêuticas (CTs), apesar de ser o seu eixo central. Explícita ou sub-repticiamente, há enunciados de profissionais do SUS, relatados por usuários(as) do CnaR, que funcionam no cotidiano fazendo da abstinência uma condição para o tratamento (Araujo e Schramm, 2017).

Em seu uso ingênuo, os termos cidadã(o) e cidadania parecem infrutíferos. Já seu uso policialesco se espraia. Lida-se com um instrumento de distinção, apontando para diferentes formas de atuação quando se detecta algo que desvie de seu modelo: trata-se de achar "quem não é nem pode ser cidadão" e instaurar meios de se lidar com esse 'fora'. Para tanto, constitui-se um léxico, sempre em mutação, para enquadrar a alteridade. Entretanto, o manejo do termo 'cracudo' parece indicar que não há passividade dessas pessoas deslocadas para a fronteira da humanidade.

\section{‘Cracudos' e o crack}

Uma mulher circula pela cena de Nova Holanda repetindo: "cracudos, cracudos"; uma camelô, às margens da Avenida Brasil, ao ver o CnaR passar, diz: "a prefeitura tem que fazer alguma coisa com esses cracudos, eles deixam uma sujeirada em tudo que é lugar"; ouve-se uma conversa, na kombi do CnaR, entre três pessoas que saíram da cena de Nova Holanda para atendimento na clínica: ao ver a mochila roxa do homem, ela diz que "é muito fashion", ele agradece e fica feliz com o reconhecimento. Ele se preocupa com sua aparência e suas roupas: "Não dá para ficar andando com a mochila toda rasgada e cheia de nós que nem as dos cracudos". Ela concorda, 
mas logo faz a ressalva de que se ele fosse em um shopping veria um monte de gente andando com roupas e mochilas rasgadas também: "Isso é moda agora". Na mesma direção, um homem diz para uma pesquisadora: “De todo jeito eu ainda tenho que arrumar um trabalho, parar de ficar no farol e parar de ficar com os noias, porque quem olha não sabe fazer essa diferença que você tá fazendo" (Rui, 2012, p. 258). Ouve-se constantemente no campo: "Não sou como eles". Nesse sentido, a difícil apreensão empírica da figura do cracudo e de suas variantes regionais não dificulta a visualização de sua funcionalidade.

Observa-se uma extensa gama de estratégias, por parte das pessoas na cena, que acabam por funcionar na diferenciação em relação a certos componentes do que constituiria tal figura. O "não sou como eles" tem como base essa diferenciação sempre relativa a certos componentes: por vezes diferencia-se pela limpeza, pelas roupas em bom estado, por não ficar deitado pelas ruas; outras vezes, por "não deixar a droga te dominar". Parece haver práticas de cuidado de si que, quando confrontadas com tal figura - mesmo que não se possa dizer que são práticas 'causadas' direta ou exclusivamente por uma vontade de diferenciação em relação a essa figura -, funcionam como uma improvisação sobre esse tema nebuloso do cracudo. Tema que desde seu início parece já em variação, uma vez que emergiria de uma certa relação com o crack; mas logo esse último é eliminado como componente principal na constituição dessa figura.

Sabe-se que 'quem olha não sabe fazer essa diferença'; assim, improvisa-se em cima dessa 'ignorância' homogeneizante. Ou seja, por meio de suas próprias práticas existenciais procura-se fazer emergir componentes que servirão para essa diferenciação, cujo funcionamento é aquele de tornar possível que se habite um espaço no qual estão presentes os componentes que podem constituir o cracudo sem se confundir com essa figura. Tal diferenciação, então, torna-se um componente existencial e, ao mesmo tempo, permite que se habite, de forma distinta, um espaço compartilhado com aquelas pessoas que podem ser chamadas, na própria cena, de cracudas. Mas tudo se complexifica, pois nessas circunstâncias uma pessoa enuncia: “cracudos, cracudos", e não se dá muita atenção a ela, já que parece haver um trabalho de diferenciação permanente acontecendo por todos os lados. As vidas e os termos entram em variação por meio dessa improvisação existencial: a cada instante emergem diferentes componentes que confrontam a figura do cracudo; novos componentes são erguidos para fundamentar tal figura, distanciando-a das vidas presentes nas cenas. Além disso, sabe-se que não se trata de colocar tais vidas em jogo quando se enuncia tal termo em uma cena, como seria o caso com denúncias de delator ou de roubo nas proximidades. Lida-se, aí, com uma tentativa de participação na gestão desse jogo, mesmo que minimamente, 
no qual a vida de quem enuncia o termo cracudos também está inserida; afinal 'quem olha não sabe fazer essa diferença'.

Entretanto, tal figura surge como um efeito direto do crack quando elevado à condição de 'centro', o que quer dizer que não se trata da substância no que ela poderia ter de concreto - as suas relações com os elementos da vida de quem a usa e, a partir daí, seus efeitos. Não se trata do crack como foco de análise, de pesquisa, como algo a que, em relação às vidas que dele fazem uso, se proporão questionamentos diversos, inclusive relacionados ao papel da mídia no dito 'poder do crack'. Sabe-se que "a população da chamada cracolândia [em São Paulo] mais do que duplicou no final de semana seguinte" (Lancetti, 2015, p. 28-29) à exibição de um quadro televisivo sobre crack; nele se informava quanto custava, onde se encontrava e seus poderes de vício instantâneo.

Nenhuma dessas questões importa quando o crack funciona como 'centro'. Mesmo quando o álcool aparece como uma variável importante em um território, pressupõe-se o crack: "Eu estou aonde? Eu tô na cracolândia. O que você acha?!" Mesmo que se viva, se façam outras coisas diferentes e desvinculadas do uso de crack, se diz: "Isso aqui é a cracolândia"; mesmo que não se saiba se tenha havido o uso de crack, pode-se dizer: "viciado"; "usuário de crack"; "dependente". É possível perceber que aquela ignorância homogeneizante é produto de um longo trabalho, no qual ao mesmo tempo se extrai uma constante das variáveis e se desvincula, ou se esvazia essa constante, da variável de 'origem', daquelas vidas sobre as quais o crack tem um efeito devastador. Esse duplo trabalho de extração e desvinculação, ou esvaziamento, é essencial para o funcionamento desses termos em um campo macropolítico. A partir desse trabalho pode-se cobrir todas as variáveis, toda a improvisação própria da vida, com esses significantes que não apenas passam a sobrevoar os locais nos quais estão presentes as pedras de crack e os corpos que delas fazem uso, mas também podem encobrir os mais diferentes modos de existência presentes nas ruas. Atualizam-se, assim, “antigas representações estigmatizantes acerca dos moradores de rua", representações de "meninos e meninas de rua, pedintes e mulheres em situação de prostituição que se fundem àquelas atribuídas aos usuários de crack, condensando e reproduzindo a partir dessa figura uma série de novas tensões sociais" (Frúgoli Jr. e Cavalcanti, 2013, p. 74).

Os termos viciado, dependente e cracudo são ouvidos mesmo quando não se sabe se tenha havido o uso de crack. Parece que o efeito mais importante desse trabalho de constituição de uma constante de um centro é o fato de que não há vínculos com as variáveis concretas: as vidas que orbitam ao redor do crack, que se encontram presas a sua força gravitacional, não se tornam casos paradigmáticos. Se fossem, seria simples confrontar tais casos com outros nos quais o crack funciona como mero componente. Portanto, o crack ganha funcionalidade quando deixa de se relacionar com o que há de 
concreto, esvazia-se e torna-se uma redundância: mesmo que o crack não vicie, ele vicia, porque o crack vicia; mesmo que o crack não mate, ele mata, porque o crack mata. Cria-se um distanciamento em relação aos efeitos das múltiplas conexões das quais aquela entre as pedras de crack e os corpos individuais é apenas uma dentre elas. Tal distanciamento é um pressuposto para a emersão do crack como droga significante (Guattari, 2012), algo que, ao ser enunciado, ao encadear outros significantes (cracudos, cracolândias), dá forma e movimento a certos agenciamentos materiais e imateriais. $\mathrm{O}$ crack como droga significante funciona como uma pequena sentença de morte. E não há melhor análise disso do que aquela feita por um usuário do CnaR: “Dizem que o crack mata em seis meses; tô nessa vida há dez anos e não morri... quer dizer, morri socialmente, como dizem, mas a carne está aqui". Momentos depois de se ouvir tal análise, veem-se pessoas que compartilham a linha de trem, andando rapidamente; suspeita-se de que se trate da polícia chegando, o que se confirma: "São os urubus", alguém diz. O autor da análise prossegue: "Eles vêm aqui, não prendem os bandidos, não prendem quem vende, aí bate na gente mesmo". Chegaram atrás da carne que ainda "está aqui".

Ao se falar 'o crack', aqui, não se pretende denotar algo 'autossuficiente', mesmo quando se trata de sua configuração 'centro'. Lida-se aí com um trabalho, com o assentamento de algo sobre um campo de forças dado, o que pressupõe conexões, ligações, como aquelas com a mídia, a polícia e a estrutura racista das instituições brasileiras - não é à toa que a guerra às drogas, no Brasil, se assenta em uma guerra constituinte dessa nação, aquela contra as pessoas negras. Ao se falar de crack, lembra-se de que "nada do que é real é autossuficiente. O fato isolado não existe": "toda experiência, tão factual ela seja, está saturada de interpretações, ideias e múltiplas conexões" (Debaise e Stengers, 2016, p. 84).

\section{A instituição e sua imposição como centro existencial}

A polícia, assim como outras instituições, parece ter a capacidade de funcionar como um centro na configuração, reconfiguração e destruição dos elementos que constituem uma existência. Sua capacidade de fechamento sobre si mesma e de autoconservação permite-lhe atuar 'sobre' essas existências protegendo-se dos efeitos que elas poderiam gerar. A instituição deixa de ser um componente, desliza para o centro e busca impor uma configuração a esses modos de existir diversos. Trata-se de instituições totais a céu aberto.

É exemplar o caso da operação conjunta da Secretaria Municipal de Desenvolvimento Social do Rio de Janeiro (SMDS) e da Polícia Militar (contando com o 'Caveirão') no final de 2013. Segundo um usuário do CnaR, esse tipo de operação se resume a “destruir tudo e 'sarquear' [verificar os anteceden- 
tes criminais] o pessoal". Uma pessoa presente na cena contou que mais de cem pessoas foram distribuídas entre o batalhão da polícia e os abrigos da assistência social. Interessante notar que tal operação aconteceu um dia depois da veiculação maciça de imagens de um homem andando entre os carros em movimento na Avenida Brasil, na altura de Nova Holanda. Concomitantemente às imagens, pronunciam-se os termos 'viciado', 'usuário de crack', 'dependente'; assim como as afirmações do tipo: "Ele está colocando em risco outras pessoas." Não se lida apenas com influência da mídia, mas com uma dupla capacidade. A primeira é a de criar um 'usuário' de crack, já que, por um lado, não se sabe se houve uso de crack e, por outro, mesmo que se supusesse que tenha havido tal uso a partir das ações do homem, é interessante verificar que aqueles que discursam acerca de uma irracionalidade causada e inerente ao uso de crack não atentam para o fato de que assim que o homem vê a polícia ele começa a correr - o que parece demonstrar que, mesmo dentro de toda essa suposta irracionalidade, o papel da polícia não se modifica: tratase de um perigo maior do que os carros e as motos passando ao seu redor. A segunda capacidade é a de criar um poder que não se restringe à influência política, mas parece ser um poder político executivo.

A análise da atuação policial, da grande mídia e da secretaria responsável pela assistência social sugere que, ao se imporem não como componentes para certas existências, mas centros, essas instituições, pelos meios dos quais dispõem, transformam os modos de existência a partir de si mesmas. Por isso as ações de diferentes instituições parecem espelhar-se entre si. Daí uma ação que combine a polícia e a assistência social e que a partir dela se possa estabelecer, a um só golpe, o crime e o criminoso, a desordem e o desordeiro, as falhas sociais e os desassistidos.

A polícia, em particular, estabelece ou detecta seus suspeitos, assim precisa 'sarquear' as pessoas; seus inimigos, que precisam desde já ser combatidos - "eles chegam batendo e depois pergunta. Muitas vezes a gente não está fazendo nada" (Oliveira, 2009, p. 131); “a polícia já chega batendo, seria bom que tivessem umas câmeras aqui, talvez eles iam se controlar mais", diz um agente comunitário de saúde (ACS) do CnaR Manguinhos -; e aqueles que deixará passar. Ainda nessa direção, o enunciado de um representante da polícia, em diálogo com o Consultório de Rua de Salvador, é exemplar: “Compreendemos o problema desses meninos [que se encontram em situação de rua e fazem uso de drogas registradas como ilegais], mas a gente não está aqui para compreender, nosso papel é reprimir. Nós vamos continuar fazendo nosso papel, e vocês o de vocês" (Oliveira, 2009, p. 131).

Há um enunciado que parece coagular todo esse funcionamento policial. Tal foi relatado por um usuário do serviço. Ele foi abordado por dois policiais que o revistaram, inclusive pediram para ele retirar um curativo que estava em sua cabeça para verificarem se havia droga escondida ali. Em seu bolso 
foram encontradas algumas 'pedras' de crack. Quando as viu, um dos policiais lhe disse: "sabia que eu podia te f... com essa quantidade de droga que você está?!" Ele tentou explicar dizendo que apenas três eram dele, o resto era 'encomenda' para alguns amigos. Depois de muito 'desenrolo', ele conseguiu ficar com suas três pedras; já a encomenda foi levada pelos policiais. Quando ouviu esse relato, outra usuária disse: "Eles são viciados também".

Vê-se que há uma capacidade de configurar, a partir de si, uma existência cujo efeito é aquele de constituir certos agrupamentos arbitrários de acordo com o modelo institucional, e que relaciona-se de forma secundária com as leis. Isso quer dizer que a nova Lei de Drogas, n. 11.343/06, ampara-se na prática policial de decisão em relação ao status de usuário ou de traficante daquela pessoa que possui (por vezes nem isso) alguma droga inscrita como ilícita, não o contrário. A lei de 2006 expõe ainda os pontos sobre os quais a decisão policial e judicial deverá se apoiar para distinguir o traficante do usuário. Os pontos podem ser agrupados em relação à substância (natureza da substância apreendida; quantidade da substância apreendida) e em relação à pessoa detida (local e condição em que se desenvolveu a apreensão; circunstâncias sociais do agente; circunstâncias pessoais do agente; conduta do agente; antecedentes). Emerge, assim, a "quase iminente e cristalina possibilidade de se acabar atingindo apenas aqueles indivíduos pertencentes à população carente, residentes em favelas e subúrbios" (Lins, 2009, p. 251). Ou seja, entende-se, aqui, a lei como efeito formal da prática policial. O "sabia que eu podia te f...?!" é o instante prévio a uma reconfiguração. Aquele sob o poder da polícia entra em um estado no qual pode se tornar usuário, pode se tornar traficante, pode ser espancado, pode ser morto. Trata-se do momento em que, com relação à vida e à morte, se é neutro, pois será a partir daquele que exerce o poder soberano de matar e deixar viver que se "tem o direito de estar vivo ou tem direito, eventualmente, de estar morto" (Foucault, 2010, p. 202). Tem-se o momento exato da irrealização do Outro (Butler, 2004). A polícia pode emergir como poder disciplinador, que encarcerará com o fim de correção; como poder soberano, que decidirá se matará ou manterá vivo; ou como abertura para $n$ desvios: o desenrolo, o arrego, o vício.

Durante o trabalho de campo, muito se ouviu sobre prisões, espancamentos e mortes. Pegam-se dois anos de prisão porque se é maior de idade e sua amiga, que é menor, está com maconha. Apanha-se muito da polícia ao ser pego com um baseado. Morre-se com uma pancada na cabeça, dada pela polícia, depois de se usar loló. Segundo a ACS do CnaR, tal pancada é calculada, pois deriva-se de um saber segundo o qual, ao se usar loló, o cérebro incha e torna-se mais vulnerável a pancadas. Não importa, aqui, se é uma crença popular ou algo passível de comprovação científica. O importante é o fato de a pancada ser desferida e o agente da ação 'esperar' maior dano de seu golpe. 
A princípio parece que se lida com uma vontade arbitrária, mas recordase que ela está assentada sobre um campo social dado. Cabe perguntar quais outros elementos estão em jogo nessas (re)configurações: vê-se uma mulher; um homem negro; um adolescente negro. Em relação àquele que ouviu "sabia que eu podia te f...?!", pergunta-se o quanto sua 'branquitude' foi um componente-chave no desenrolo, tendo em vista que, sobre esse tema, um ACS relatou que uma situação semelhante aconteceu com outro usuário branco do CnaR, e fez a ressalva de que parecia se tratar de exceções em relação à regularidade do tratamento violento usual da polícia. Ainda uma indagação que atravessa todas as situações: e se não fosse na favela? Sobre um campo social dado, portanto, a 'mania de generalizações' desempenha uma importante função.

Lima Barreto (2010, p. 177) já salientava que a "polícia, não sei como e por quê, adquiriu a mania das generalizações, e as mais infantis"; por isso, continua o autor, "todo cidadão de cor há de ser por força um malandro; e todos os loucos hão de ser por força furiosos e só transportáveis em carros blindados". A funcionalidade dessa mania de generalização é visível no enquadramento do 'avião' como traficante. O avião é personagem fronteiriço: encontra-se entre quem compra e quem vende as drogas tidas como ilícitas, por vezes se confunde com um ou outro. Pode se tratar de uma pessoa que comprou certa quantidade a partir de uma verba coletiva que impõe o compartilhamento do produto entre o grupo, ou seja, não há lucro (como parece ser o caso daquele que foi abordado pela polícia e perdeu as pedras que iria entregar para seus amigos); ou que passa a fazer negócios para garantir um lucro que sustentará seu consumo (Barbosa, 1998).

Ao tornar-se centro e manipular os componentes constituintes de modos de existir, pode-se circunscrevê-los arbitrariamente, submetê-los a certos cálculos e, principalmente, traçar e modular como um horizonte permanente a morte. A multiplicação desse poder pelo campo social, o fato de as mais diferentes instituições - sejam elas a polícia, o tráfico, sejam também os serviços de saúde - disporem da morte, de modo direto ou indireto, de tal forma, concretizam uma democratização da soberania. Vê-se, assim, toda a exatidão da análise de um educador de rua quando, em conversa informal, diz: "As cracolândias são campos de concentração". Cabe ainda refletir sobre como, de modo subjacente às justificativas para o não acolhimento de certas pessoas classificadas como 'de rua' ou 'cracudas' e o não tratamento de pessoas que não estão em situação de abstinência, encontra-se o enunciado "sabia que eu podia te f...?!" Se as instituições se espelham, o rosto que elas compartilham 
é de um Estado policial. Daí parecer que o funcionamento do CnaR emerge como contraponto a esse estado de coisas.

\section{O devir do Consultório na Rua}

O CnaR não lida apenas com as cenas na rua, mas também com uma rede de serviços e circunscrições administrativas, o que quer dizer que se estipula um organograma no qual desenham-se os encaminhamentos possíveis das pessoas usuárias do CnaR a outros serviços. Além dessa relação formal entre instituições pertencentes a uma rede ideal de funcionamento integrado, existem interações concretas incessantes entre o CnaR e outras instituições interações que a equipe busca gerir, pois sabe que se aliar momentaneamente a uma certa instituição pode ter como efeito a destruição daquilo que faz seu trabalho funcionar: o vínculo com as cenas. Por isso, a recusa, por exemplo, de parcerias na rua com a SMDS, instituição percebida pelas pessoas nas cenas como 'o recolhimento'.

Esse vínculo é cuidado o tempo todo. Não apenas por seus efeitos relativos à relação equipe/pessoa usuária, mas também por seus efeitos sobre outras ações institucionais. Momentaneamente, há uma oscilação no funcionamento normal das instituições, e as pessoas sabem disso: “Vocês [equipe do CnaR] podem ficar aqui mais um pouco? É que quando vocês tão aqui a polícia não entra" (Abib, 2014, p. 89), disse uma pessoa a uma equipe de CnaR em Porto Alegre; "[t]em se mostrado fundamental nossa presença como forma de garantir os atendimentos" (Domanico, 2006, p. 134), relatou integrante de projeto de redução de danos acerca do atendimento de pessoas usuárias de crack em outros serviços de saúde. Em uma das cenas atendidas pelo CnaR Manguinhos, um representante do tráfico largou o pedaço de madeira que costuma carregar e buscou uma forma adequada, segundo seus critérios, de organizar as pessoas para o atendimento da equipe. Esse vínculo, então, funciona como uma aliança em relação a outras instituições.

É ilustrativo o caso, ocorrido em 2013, de um rapaz que levou um tiro na perna dado pelo tráfico e foi atendido pelo enfermeiro da equipe. Além desse atendimento clínico, a equipe conseguiu contato com a mãe do rapaz. Ela informou que no dia seguinte poderia levá-lo para casa. Apesar de usufruir de fluxos de encaminhamentos com certos abrigos, não se conseguiu uma vaga de pernoite para o rapaz. Ele decidiu dormir nos gramados próximos à sede do consultório, para assim ser facilmente encontrado, no dia seguinte, pela equipe e sua mãe.

Na manhã seguinte, o ACS, ao se aproximar do local combinado, visualizou uma equipe da SMDS colocando o rapaz dentro da van da instituição. O 
rapaz explicou insistentemente o motivo de estar ali - ou seja, estava aguardando a mãe levá-lo para casa - e disse que não queria sair dali; mesmo assim, a equipe da SMDS não interrompeu sua ação. Ao perceber o que ocorria, o ACS correu para a clínica e chamou o enfermeiro. Os dois foram em direção à van com uma cadeira de rodas para poder tirar o rapaz dali. $\mathrm{O}$ enfermeiro repetiu o motivo de o rapaz estar ali. Mesmo tendo como resposta "você está atrapalhando nosso trabalho", conseguiu retirar o usuário da van, permitindo que ele encontrasse sua mãe.

Instaura-se um curto-circuito institucional. Busca-se o desassistido, persegue-se o criminoso, mas impõe-se um usuário de um serviço de saúde. Parece que essas equipes, ao direcionarem o olhar para o $\mathrm{CnaR}$, veem de relance o rosto do Estado, porém não conseguem reconhecê-lo. Como demonstra o momento em que ao chegar a uma cena a equipe viu pessoas correndo, outras sendo empurradas e atingidas por spray de pimenta jogado por policiais; alguns desses se concentravam em expulsar pessoas e destruir seus quartinhos. Logo que percebeu a aproximação da equipe, um policial direcionou seu fuzil para o carro; a equipe começou a protestar, não parecendo estar disposta a sair dali, até que baforadas de spray começaram a ser jogadas em sua direção.

Efetivamente algo acontece, e talvez seja o caso, pelo menos momentaneamente, de olhar a potência do acontecimento e menos a arbitrariedade cotidiana da polícia. O que dizer quando esta última deixa de reconhecer o Estado e ataca uma equipe de um serviço de saúde? Um enunciado, relatado em uma tese sobre a implementação de programas de redução de danos em diferentes lugares do Brasil, é interessante: "mas vocês são tudo noia mesmo", diz uma pessoa para a equipe de redução que a atende; "por que ficar aqui no meio da gente, falando sobre como usar crack, camisinhas, essas coisas... Aguentando a nossa noia, voltando sempre apesar das brigas e ainda sendo amigo da gente? Não é coisa de gente normal, não" (Domanico, 2006, p. 194). Poder-se-ia dizer que se trata de uma identificação, mas há algo diferente. Talvez seja exatamente sobre essa coisa que não é de gente normal que a atenção deva ser focada. Coisa que permite que o termo 'noia' desvincule-se do crack e vincule-se a um certo modo de funcionamento, tornado visível pelos verbos sempre no gerúndio, cujos efeitos são aqueles de constituir vínculos por meio dos quais as existências se tocam, se transformam e se potencializam. Esses efeitos correm em várias direções - nas equipes, nas pessoas na rua, nas drogas, nos termos, na cidade. Lida-se com algo que se dá no meio, algo que faz variar ambos os polos - a equipe e as pessoas na rua - tornando-os, mesmo que por um breve instante, diferentes de si mesmos. Chama-se esse algo que acontece no meio de 'devir', segundo o qual se cria incessantemente a 'clínica na rua'. A emergência dela não pode ser analisada por meio de seu resultado, apenas pela qualidade das aberturas para 'devir' que o processo 
de criação permite. Assim, só é possível criar uma clínica na rua quando se cria 'diante' de quem está na rua.

Apenas quando se cria 'diante' de quem está na rua é possível diferenciarse e conjurar as formas institucionais majoritárias em relação à rua. É um movimento complexo de conjuração e de um vir a ser duplo: cria-se 'diante' de quem está na rua para que quem esteja na rua se torne, também, outra coisa (Deleuze e Guattari, 1997). Pode-se dizer, talvez, que se trata de um processo que supõe 'responsabilidade institucional' e 'potência minoritária'.

Responsabilidade institucional 'diante' de uma minoria: grupos suscetíveis ou vulnerados mediante certo estado de coisas concreto, como também uma qualificação abstrata segundo a qual se encontram aquém de um modelo ideal, gerando maior propensão a sofrer danos. Há, aí, uma distribuição geopolítica de vulnerabilidade (Butler, 2004), potencialmente desigual, em que alguns sujeitos e comunidades são mais suscetíveis, de acordo com condições sociais e políticas específicas, ao risco e à concretização de situações de vulneração. A responsabilidade institucional emerge de uma capacidade guardada pelas instituições de se salvaguardar segundo os meios de que dispõem. Tal capacidade protetiva em relação à própria existência passa a funcionar como chave para aberturas em relação às minorias: passa-se a ser afetada e modulada por elas, pois a proteção institucional garante uma resiliência existencial. É estabelecido um processo cujo objetivo é "fazer oscilar, rachar, o caráter de totalização de uma instituição", o que torna possível que "esta, em vez de girar em torno de si mesma como estrutura, pode adquirir uma consistência subjetiva e instaurar todo tipo de modificações e novos questionamentos" (Guattari, 2004, p. 69).

Por sua vez, a potência minoritária é a única que pode desviar as instituições de seus fechamentos sobre si mesmas, e assim possibilitar criações. Agora, diz-se menos sobre o estado de coisas e mais acerca da criatividade das minorias; criatividade que permite que mesmo em espaços devastados criem-se territórios de vida. Apenas tornando-se componente desses territórios, dessas existências, agenciando-se com elas, é que passa a ser possível para uma instituição 'devir'.

\section{Considerações finais}

Buscou-se distinguir dois polos de ação institucional. Há aquele no qual a instituição busca configurar, a partir de si, as diferentes existências que encontra, instaurando-se como um centro. Diferentes pessoas e grupos, independentemente da complexidade de suas vidas, podem ser, no primeiro momento do encontro com uma instituição, classificados de acordo com o vocabulário institucional. Classificação que não só guiará 
as ações sobre tais pessoas e grupos como também tenderá a fazer tais existências orbitarem ao redor da instituição. Trata-se de jogo de múltiplos protagonistas institucionais no qual, de centro em centro, a trajetória de diversas existências já é demarcada.

O outro polo se caracteriza por um modo segundo o qual a instituição se oferece como um apoio às existências. Para tanto, a instituição passa a ter sua existência modificada; ela se abre às transformações derivadas do contato com as alteridades que encontra e busca acolher. Essa abertura à mudança provém do que se chamou 'responsabilidade institucional', e os efeitos transformadores decorrem de uma 'potência minoritária'. A possibilidade de inovar os serviços de saúde e promover inovações a partir deles, concretizando, por diferentes meios, os princípios norteadores do SUS (universalidade, equidade e integralidade), parece ser efeito do aumento da permeabilidade desses serviços às variações promovidas pelas alteridades que encontra. O CnaR parece ocupar esse polo. Apresenta-se como uma inovação nos serviços de saúde e promove modificações, mesmo que momentâneas, nos outros serviços que atuam nas cenas de uso de crack ou atendem pessoas que os frequentam, devido à criação e à recriação de seu modo de funcionar mediante um encontro entre heterogêneos como heterogêneos: entre um serviço de saúde aberto à transformar-se e pessoas dispostas a usarem-no de acordo com suas existências.

Talvez uma frase, em um desenho produzido durante uma atividade proposta pelo CnaR, possa sintetizar essa relação: “Cracudos, vamos nos unir para sair dessa vida". Poder-se-ia pensar que tal frase diz algo sobre deixar de ser cracudo, mas mesmo que se trate disso, se deixará de ser cracudo como cracudo, e associado a outros. Não se lida com o reconhecimento de uma fraqueza ou impotência diante do crack, reconhecimento que possibilitaria superá-lo. Vislumbra-se uma associação de pessoas usuárias de crack? Quem sabe? Há algo nessa frase, talvez um 'gérmen' não integrado, um momento no qual não há mais diferenciação em relação à figura do cracudo, mas sim distinção de seu elemento virtual. Existe algo que não se assemelha a nada relativo ao cracudo, mas que ao mesmo tempo abre brechas para toda a sua potência desconhecida e funciona como uma avaliação do estado de coisas. Uma potência que pode avaliar e transformar existências, inclusive aquelas institucionais que buscam atuar junto a ela. Há, assim, um duplo funcionamento que possibilita o chamado: "Vamos nos unir para sair dessa vida".

\section{Financiamento}

Este artigo resultou, com algumas modificações, da tese de doutorado em Bioética, Ética aplicada e Saúde coletiva, de Erick Araujo, intitulada A vida em cenas de uso de crack : ensaio de análise institucional e bioética, apresentada 
à Universidade Federal Fluminense, Niterói, Rio de Janeiro, em 2016, com financiamento da Coordenação de Aperfeiçoamento de Pessoal de Nível Superior por meio de bolsa de doutorado.

\section{FUNCIONAMIENTO DE INSTITUCIONES EN AMBIENTES DE USO DE CRACK: UN ESTUDIO ETNOGRÁFICO}

Resumen En la investigación que dio origen a este artículo, realizada en la ciudad de Rio de Janeiro, Brasil, entre el 2013 y el 2015, se analizó el funcionamiento de las instituciones relacionadas a los ambientes de uso de crack y a las personas que los frecuentan, con el objetivo de hacerlas inteligibles. Desde la perspectiva del encuentro entre el Consultorio en la Calle y las personas presentes en estos ambientes que se convirtieron, o no, es sus usuarios, se buscan esclarecer las relaciones establecidas entre esta población y el crack, el propio Consultorio en la Calle e instituciones como la policía, la asistencia social y otros servicios de salud. Con base en los datos producidos a partir de la etnografía, se pueden distinguir dos polos de acción institucional: uno más cercano a provocar la muerte o dejar vivir, ejerciendo incluso un poder soberano de decisión; y otro de acuerdo con el cual la institución se ofrece como apoyo existencial, para lo cual se modifica a partir del encuentro con aquellas personas a las que busca atender. Se concluye que las innovaciones existentes y posibles en los servicios de salud, se derivan de este funcionamiento a partir del cual las instituciones, por medio de lo que se llamó 'responsabilidad institucional', se abren a las transformaciones promovidas por una 'potencia minoritaria'.

Palabras clave población en situación de calle; crack; Sistema Único de Salud.

\section{Referências}

ABIB, Leonardo T. Crônicas urbanas: consultório na rua, população em situação de rua, clínica menor e outras histórias. 150f. Dissertação (Mestrado em Educação em Ciências: Química da Vida e Saúde) - Universidade Federal do Rio Grande, Rio Grande, 2014.

ANTUNES, Valeska H. Consultório na Rua de Manguinhos: compartilhando experiências. Apresentação oral. Rio de Janeiro: Fiocruz, 2013. Disponível em: <http://189.28.128.100/ dab/docs/portaldab/documentos/Rio_de_ Janeiro_Valeska_Antunes.pdf $>$. Acesso em: 13 dez. 2018.

ARAUJO, Erick; SCHRAMM, Fermin R. Os princípios da clínica na rua e os funcionamentos do crack. Bioética, Brasília, v. 25, n. 3, p. 473-481, 2017.

ARDOINO, Jacques; LOURAU, René. As pedagogias institucionais. São Carlos: Rima, 2003.
BARBOSA, Antônio C. R. Um abraço para todos os amigos: algumas considerações sobre tráfico de drogas no Rio de Janeiro. Niterói: EdUFF, 1998.

BAREMBLITT, Gregório. Compêndio de análise institucional e outras correntes. Rio de Janeiro: Rosa dos Tempos, 1998.

BARRETO, Lima. Diário do hospício e cemitério dos vivos. São Paulo: Cosac Naify, 2010.

BUTLER, Judith. Precarious life: the powers of mourning and violence. London: Verso, 2004.

DEBAISE, Didier; STENGERS, Isabelle. L'insistance des possibles: pour un pragmatisme spéculatif. Multitudes, Paris, v. 4, n. 65, p. 82-89, 2016.

DELEUZE, Gilles. Nietzsche et la philosophie. Paris: PUF, 2010. 
DELEUZE, Gilles; GUATTARI, Félix. Mil platôs: capitalismo e esquizofrenia. v. 3. São Paulo: Editora 34, 1996.

DELEUZE, Gilles; GUATTARI, Félix. O que é a filosofia? Rio de Janeiro: Editora 34, 1997.

DOMANICO, Andrea. 'Craqueiros e cracados: bem vindo ao mundo dos noias!': estudo sobre a implementação de estratégias de redução de danos para usuários de crack nos cinco projetos-piloto do Brasil. $220 \mathrm{f}$. Tese (Doutorado em Ciências Sociais) - Universidade Federal da Bahia, Salvador, 2006.

ENGSTROM, Elyne M.; TEIXEIRA, Mirna B. Equipe 'Consultório na Rua' de Manguinhos, Rio de Janeiro, Brasil: práticas de cuidado e promoção da saúde em um território vulnerável. Ciência \& Saúde Coletiva, Rio de Janeiro, v. 21, n. 6, p. 1.839-1.848, 2016.

FOUCAULT, Michel. O poder psiquiátrico. São Paulo: Martins Fontes, 2006.

FOUCAULT, Michel. História da sexualidade I: a vontade de saber. 18. ed. São Paulo: Graal, 2007.

FOUCAULT, Michel. Segurança, território, população. São Paulo: Martins Fontes, 2008.

FOUCAULT, Michel. Em defesa da sociedade. São Paulo: Martins Fontes, 2010.

FOUCAULT, Michel. A história da loucura na idade clássica. 9. ed. São Paulo: Perspectiva, 2012.

FRÚGOLI JR., Heitor; CAVALCANTI, Mariana. Territorialidades da(s) cracolândia(s) em São Paulo e no Rio de Janeiro. Anuário Antropológico II, Brasília, v. 38, n. 2, p. 73-97, 2013.
GUATTARI, Félix. O inconsciente maquínico: ensaios de esquizo-análise.Campinas: Papirus, 1988

GUATTARI, Félix. Psicanálise e transversalidade: ensaios de análise institucional. São Paulo: Ideias e Letras, 2004

GUATTARI, Félix. La révolution moléculaire. Paris: Les Prairies Ordinaires, 2012.

LANCETTI, Antonio. Contrafissura e plasticidade psíquica. São Paulo: Hucitec, 2015.

LINS, Emmanuela V. A nova Lei de Drogas (lei n. 11.343/2006) e o usuário: a emergência de uma política pautada na prevenção, na redução de danos, na assistência e na reinserção social. In: NERY FILHO, Antônio et al. (orgs.). Toxicomanias: incidências clínicas e socioantropológicas. Salvador: EdUFBA, Cetad, 2009. p. 243-267.

OLIVEIRA, Mírian G. P. N. Consultório de Rua: relato de uma experiência. 151f. Dissertação (Mestrado em Saúde Coletiva) - Universidade Federal da Bahia, Salvador, 2009.

RIBEIRO, Vladimir M. L. A partir de Guattari: uma política da existência. 392 f. Tese (Doutorado em Filosofia) - Universidade Federal do Rio de Janeiro, Rio de Janeiro, 2018.

ROMANINI, Moises; ROSO, Adriane. Midiatização do crack e estigmatização: corpos habitados por histórias e cicatrizes. Interface: Comunicação, Saúde e Educação, Botucatu, v. 18, n. 49, p. 363-376, 2014.

RUI, Taniele C. Corpos abjetos: etnografia em cenários de uso e comércio de crack. 355f. Tese (Doutorado em Antropologia Social) - Universidade Estadual de Campinas, Campinas, 2012. 